\title{
Neuropsychological test results and symptoms among workers with well-defined long-term exposure to lead
}

\author{
C HOGSTEDT, ${ }^{13}$ MONICA HANE, ${ }^{1}$ A AGRELL' AND L BODIN ${ }^{2}$ \\ From the Department of Occupational Medicine, ${ }^{1}$ Regional Hospital, S-701 85 Örebro, Department of \\ Statistics, ${ }^{2}$ University of Örebro, S-701 30 Örebro, and Section of Occupational Medicine, ${ }^{3}$ National \\ Board of Occupational Safety and Health, S-171 84 Solna, Sweden
}

ABSTRACT Lead intoxication is a classical environmental hazard that can cause encephalopathy. During recent years several studies have suggested poor performances in psychological tests and increased numbers of subjective symptoms among workers with comparatively low blood lead concentrations. Forty-nine long-term lead-exposed male workers with time-weighted average blood lead concentrations between 1.3 and $3.3 \mu \mathrm{mol} / /$ calculated from at least seven years' results have been compared with a referent group of 27 male industrial workers with normal blood lead concentrations and comparable intellectual backgrounds. Several indices of exposure were used. Both groups were examined with neuropsychological tests and a questionnaire covering neuropsychiatric symptoms. The exposed group performed less well in 11 of 14 non-verbal tests, and there were significant differences in tests of memory and reaction time. A non-linear doseeffect trend was indicated. The results are in accordance with those found in similar studies, and it is concluded that the blood lead concentration should be below $2 \cdot 5 \mu \mathrm{mol} / 1$ to avoid the effects shown in this study.

Lead intoxication is a classic environmental and occupational hazard that in high doses causes encephalopathy with symptoms such as irritability, depressiveness, and concentration and memory disturbances. During recent years, several studies have suggested poor performance in psychological tests of intellectual functions ${ }^{1-7}$ and an increased number of subjective symptoms ${ }^{89}$ among workers with comparatively low blood lead concentrations. The exposure, however, has been either short or not registered regularly. Therefore, it seemed important to study workers exposed for many years with blood lead analyses performed regularly during the time of their exposure.

\section{Methods and material}

\section{LEAD EXPOSURE}

The register of workers who had had their blood lead concentrations analysed at the laboratory of the department of occupational medicine in Örebro during 1967-79 was chosen as the source of subjects. The register contained information about the date

Received 18 November 1981

Accepted 7 June 1982 and blood lead value for each measurement, and a time-weighted average of blood lead was calculated for each subject in the exposed group in the same way as Hänninen et al. ${ }^{4}$

TWA B-Pb $=\sum_{i=1}^{n-1} \frac{0.5 \times\left(P_{i+1}+P_{i}\right) \times\left(t_{i+1}-t_{i}\right)}{t_{n}-t_{1}}$

where $t_{i}$ is the time of measurement " $i$ " and $P_{i}$ is the blood lead level $(\mathrm{B}-\mathrm{Pb})$ at measurement " $\mathrm{i}$, " " $\mathrm{i}+1$ " is the measurement following " $i$," and $t_{n}$ the time of the last measurement.

At the time of the present investigation haemoglobin concentration, the present state of blood lead (B-Pb), and zinc protoporphyrin (B-ZPP) were examined. All blood lead measurements were conducted by the same laboratory during the whole period of measurements and by the same atomic absorption spectrophotometer (Perkin Elmer 403). Blood lead concentration has been recorded two to four times a year in the exposed group. The laboratory had participated regularly in interlaboratory comparisons with approved results. B-ZPP was measured from duplicate samples by the laboratory at the department of occupational medicine in Lund. ${ }^{10}$ 


\section{SUBJECTS}

The exposed group was composed of male workers who had been controlled for at least seven years, were still exposed, and who had a time-weighted average of blood lead (TWA B-Pb) between 1.3 to $3.3 \mu \mathrm{mol} / \mathrm{l}$.

To achieve comparable motivation for referents to score maximally in the neuropsychological tests male workers who had been controlled for blood lead concentration by the same laboratory on at least three occasions and had never had a single $\mathrm{B}-\mathrm{Pb}$ above $1 \cdot 0 \mu \mathrm{mol} / \mathrm{l}$ were chosen as the referent group. The workers had usually been told the $\mathrm{B}-\mathrm{Pb}$ concentrations as they were taken. The purpose of the study was explained to both groups. It was mentioned in the introduction to the groups that some epidemiological studies had shown also that low blood lead concentrations could have an effect on the central nervous system but that other studies had not shown any differences between exposed and non-exposed. To get the same educational background a restriction was introduced of at the most 10 years of school education.

We identified 53 lead-exposed workers and 37 referents according to the criteria mentioned. Nine of the referents did not attend the briefing sessions preceding the examinations and could thus not be included. The lower participation of the referents might be due to lack of interest but also to a higher proportion of shift workers among the referents $(55 \%)$ than among the exposed $(24 \%)$. Four of the exposed and one of the referents did not want to participate in the study. Thus the group under study consisted of 49 exposed workers and 27 referents. The exposed workers were mainly employed at secondary lead smelters and battery factories. The referents were employed at a steel wire industry, machinery shops, or worked with ammunition control.

The mean age of the exposed group was 48 years and 47 years in the control group, but the age distribution was somewhat wider among the controls. The groups did not differ in duration of school education, exposure to organic solvents, alcohol consumption, prevalence of head injuries, or in undergoing treatment for high blood pressure or any other known chronic disease that might influence the central nervous system. Eighteen of the exposed and 12 of the controls (born 1935 or later) had undergone intelligence tests when entering the army, and both groups performed equally well in these tests.

The exposed group had on average been working for 18 years with lead compared with six years in the referent group. The exposed group had as a rule been working at the same industry during the whole period of exposure, but the blood lead controls did not start at the clinic of occupational medicine until 1967. The working environment has been improved during the past decade, but interviews with older workers and a few lead blood tests from the early 1960 s indicate that the conditions during the ' $60 \mathrm{~s}$ were equal to the conditions during the ' $40 \mathrm{~s}$ and ' $50 \mathrm{~s}$. The mean timeweighted average blood lead in the exposed group was $2.3 \mu \mathrm{mol} / \mathrm{l}$ ranging from 1.3 to $3.3 \mu \mathrm{mol} / \mathrm{l}$. Twothirds of the exposed group had a value between $2 \cdot 1$ and $2.5 \mu \mathrm{mol} / \mathrm{l}$. The average of the highest single blood lead value among the exposed group was $3 \cdot 1$ $\mu \mathrm{mol} / \mathrm{l}$. Of the 49 exposed subjects, $14 \mathrm{had}$ on one occasion at least exceeded the Swedish biological threshold limit value of $3.3 \mu \mathrm{mol} / \mathrm{l}$. The mean of present blood lead concentration at the time of the study was $2.0 \mu \mathrm{mol} / \mathrm{l}$ among the exposed group and $0.7 \mu \mathrm{mol} / \mathrm{l}$ among the referents. The mean B-ZPP among the exposed group was $2 \cdot 5 \mu \mathrm{g} / \mathrm{gHb}$ and among the controls $1 \cdot 0$.

\section{BATTERY OF PSYCHOLOGICAL TESTS}

Collaborative work between various groups of Swedish psychologists has resulted in a battery of 13 psychological tests to be used in studies of neurotoxic substances. The battery was standardised on an unselected Swedish population. " The classification of tests is based on a factor analysis carried out on a sample of 99 subjects at the age of 16 and pupils in the last class of the compulsory school, thus reflecting the unrestricted variation in every variable. The first factor included tests of vocabulary - that is, the type of tests regarded as being robust in cases of diffuse organic brain damage. The second factor included tests where both visual perception and cognitive processes are supposed to be important (logical factor). The third factor covered tests where the cognitive components are supposed to be of minor importance and the scores mainly based on perceptual speed. The fourth factor consisted of tests that require eye-hand co-ordination, called psychomotor tests. The memory tests did not come out as a separate factor in the factor analysis due to reduced variation in the studied sample but gave a separate factor in groups with larger standard deviations. The test battery is briefly described by Hogstedt $e t$ al. ${ }^{12}$

A simple reaction time test was added to the test battery-to put out a light as fast as possible when lit 160 times during 10 minutes with random time intervals. The results are given in milliseconds (msec).

One test of vocabulary was excluded since it turned out to be too difficult and the auditory perception and retention (learning) test in the original battery was substituted with a more sensitive test measuring the same ability. ${ }^{13}$ Table 1 describes the tests given and which tests loaded high on each factor. The reliabilities of the tests are between $0 \cdot 74$ and $0.94 .^{11}$ 
Table 1 Raw scores and age-adjusted scores on subtests for exposed group $(n=49)$ and control group $(n=27)$

\begin{tabular}{|c|c|c|c|c|c|c|c|}
\hline \multirow[t]{3}{*}{ Factor } & \multirow[t]{3}{*}{ Subtest } & \multicolumn{4}{|c|}{ Raw score* } & \multicolumn{2}{|c|}{ Age-adjusted score $\dagger$} \\
\hline & & \multicolumn{2}{|c|}{ Exposed } & \multicolumn{2}{|c|}{ Controls } & \multirow{2}{*}{$\frac{\text { Exposed }}{\text { Mean }}$} & \multirow{2}{*}{$\begin{array}{l}\text { Controls } \\
\text { Mean }\end{array}$} \\
\hline & & Mean & $S D$ & Mean & $S D$ & & \\
\hline $\begin{array}{l}\text { Vocabulary } \\
\text { Logical function }\end{array}$ & $\begin{array}{l}\text { Synonyms } \\
\text { Figure class } \\
\text { Unfolding } \\
\text { Block } \\
\text { VGA III }\end{array}$ & $\begin{array}{l}18 \cdot 1 \\
18 \cdot 7 \\
23 \cdot 6 \\
22 \cdot 4 \\
44 \cdot 1\end{array}$ & $\begin{array}{l}5 \cdot 6 \\
4 \cdot 7 \\
6 \cdot 5 \\
6 \cdot 3 \\
8.5\end{array}$ & $\begin{array}{l}17 \cdot 9 \\
20 \cdot 4 \\
23 \cdot 7 \\
24 \cdot 5 \\
42 \cdot 9\end{array}$ & $\begin{array}{l}5 \cdot 8 \\
4 \cdot 2 \\
8 \cdot 2 \\
6 \cdot 1 \\
7 \cdot 1\end{array}$ & $\begin{array}{l}4 \cdot 5 \\
4 \cdot 3 \\
4 \cdot 6 \\
4 \cdot 6 \\
5 \cdot 0\end{array}$ & $\begin{array}{l}4 \cdot 3 \\
5 \cdot 0 \\
4 \cdot 6 \\
5 \cdot 2 \\
4 \cdot 1\end{array}$ \\
\hline Perceptual speed & $\begin{array}{l}\text { Digit symbols } \\
\text { Dots speed } \\
\text { Dots accuracy } \\
\text { Same number }\end{array}$ & $\begin{array}{c}37 \cdot 3 \\
629 \\
3 \cdot 1 \\
77 \cdot 1\end{array}$ & $\begin{array}{c}12 \cdot 8 \\
123 \\
2 \cdot 4 \\
14 \cdot 0\end{array}$ & $\begin{array}{r}40 \cdot 0 \\
645 \\
2 \cdot 4 \\
82 \cdot 0\end{array}$ & $\begin{array}{c}14 \cdot 6 \\
140 \\
2 \cdot 1 \\
12 \cdot 1\end{array}$ & $\begin{array}{l}4 \cdot 6 \\
4 \cdot 3 \\
4 \cdot 3 \\
4 \cdot 5\end{array}$ & $\begin{array}{l}5 \cdot 1 \\
4 \cdot 7 \\
5 \cdot 0 \\
5 \cdot 1\end{array}$ \\
\hline Psychomotor function & $\begin{array}{l}\text { Bolt test } \\
\text { Pins } \\
\text { Cylinders }\end{array}$ & $\begin{array}{l}23 \cdot 3 \\
26 \cdot 1 \\
74 \cdot 2\end{array}$ & $\begin{array}{l}4 \cdot 4 \\
4 \cdot 0 \\
7 \cdot 6\end{array}$ & $\begin{array}{l}23.6 \\
25 \cdot 6 \\
76.9\end{array}$ & $\begin{array}{l}5 \cdot 3 \\
4 \cdot 6 \\
8 \cdot 0\end{array}$ & $\begin{array}{l}3 \cdot 9 \\
4 \cdot 5 \\
4 \cdot 1\end{array}$ & $\begin{array}{l}4 \cdot 0 \\
4 \cdot 4 \\
4 \cdot 7\end{array}$ \\
\hline Memory & Benton, errors & $6 \cdot 6$ & $2 \cdot 6$ & $5 \cdot 1$ & $2 \cdot 2$ & $3 \cdot 4$ & $4 \cdot 6$ \\
\hline Learning & Claeson-Dahl & 134 & 67 & 84 & 75 & 189 & 138 \\
\hline Reaction time & Reaction time & 441 & 94 & 404 & 62 & 413 & 376 \\
\hline
\end{tabular}

*A higher value expresses a better performance on all tests except Dots accuracy, Benton, Claeson-Dahl, and reaction time test.

+Stanine scores are given for all tests except learning test and reaction time test. These tests are not included in standard battery.

For reviews of the use of psychometric techniques in environmental studies see Hogstedt et $a l^{12}$ and Valciukas and Lilis. ${ }^{14}$

\section{QUESTIONNAIRE}

A questionnaire with 16 questions covering neuropsychiatric symptoms was administered to the subjects. The questionnaire has been tried out on workers exposed to solvents and has been constructed in order to reflect neuropsychiatric symptoms as sensitively as possible. ${ }^{15}$ The symptom frequency in this questionnaire has been shown to be higher among several groups exposed to organic solvents compared with referents, and a high rate of positive answers seems to predict chronic neuropsychiatric disturbances. ${ }^{16}$

\section{PROCEDURE}

One part of the testing was conducted in groups of at the most five subjects and another part individually. The group examinations were conducted during the mornings (one and a half hours) and the subjects came back during the afternoon (one and a half hours) for their individual examinations. The shift workers were always tested when they were on the morning shift. The psychological test battery was always presented in the same order and with the regular breaks in the same way for all subjects. Two psychologists and one specially trained nurse conducted the examinations at the industries concerned. The testers knew that the controls were working in other industries than the exposed group, but the exposure measurements were not known to the investigators at the time of examination.
STATISTICAL ANALYSES OF DATA

The overall differences in performances in the nonverbal psychological tests between the exposed group and the referents were analysed by Hotelling $T^{2} .{ }^{17}$ Hotelling $\mathrm{T}^{2}$ is a generalisation of the common $t$ test that makes it possible to compare simultaneously the groups in a large number of variables at a given level of significance. The positive and the negative differences, however, add equally to the $T^{2}$, which must be kept in mind when evaluating the results.

In studies of intellectual capacity it is important that age does not confound the results and the age regressions were taken from a sample of non-exposed workers $(n=138)$ used as a control group in a study of car painters. ${ }^{1819}$ That control group had been divided into five age groups ( $\leqslant 24$ years, $25-34$ years, etc) and the results for each subgroup transformed to a normally distributed stanine scale. A stanine scale has nine steps (1-9), the mean is 5 and the standard deviation is 2 . The transformation matrix for the subtest "digit symbol" is given as an example in table 2. A raw score of 44 corresponds to stanine score 3 if the subject is under 25 years-a performance clearly below the mean-and to stanine score 7 if the subject is over 54 -a performance clearly above the mean. The learning test and the reaction time test were not included in the standard battery, and the age regression for these two tests was taken from the internal control group and another external material (F Gamberale, personal communication). These materials, however, were too small to allow for normalisation of the scores, and a simple linear transformation to age-adjusted scores was used.

The factor analysis carried out on an unrestricted 
Table 2 Transformation from raw scores to stanine scores for subtest "digit symbol"

\begin{tabular}{|c|c|c|c|c|c|c|c|c|c|c|}
\hline \multirow[t]{2}{*}{ Age } & \multicolumn{10}{|c|}{ Stanine score } \\
\hline & $I$ & 2 & 3 & 4 & 5 & 6 & 7 & 8 & 9 & $N$ \\
\hline $\begin{array}{l}\leqslant 24 \\
25-34 \\
35-44 \\
45-54 \\
\geqslant 55 \\
\text { Total group }\end{array}$ & $\begin{array}{l}0-28 \\
0-21 \\
0-19 \\
0-15 \\
0-20 \\
0-20\end{array}$ & $\begin{array}{l}29-39 \\
22-32 \\
20-31 \\
16-21 \\
21-24 \\
21-26\end{array}$ & $\begin{array}{l}40-44 \\
33-41 \\
32-35 \\
22-29 \\
25-27 \\
27-32\end{array}$ & $\begin{array}{l}45-46 \\
42-47 \\
36-42 \\
30-33 \\
28-30 \\
33-39\end{array}$ & $\begin{array}{l}47-55 \\
48-53 \\
43-47 \\
34-39 \\
31-36 \\
40-46\end{array}$ & $\begin{array}{l}56-64 \\
54-57 \\
48-50 \\
40-46 \\
37-41 \\
47-52\end{array}$ & $\begin{array}{l}65-69 \\
58-61 \\
51-53 \\
47-52 \\
42-44 \\
53-59\end{array}$ & $\begin{array}{l}70-73 \\
62-64 \\
54-57 \\
53-57 \\
45-47 \\
60-64\end{array}$ & $\begin{array}{l}74-90 \\
65-90 \\
58-90 \\
58-90 \\
48-90 \\
65-90\end{array}$ & $\begin{array}{r}22 \\
30 \\
27 \\
25 \\
34 \\
138\end{array}$ \\
\hline
\end{tabular}

Table 3 Means, standard deviations, and p-values from $t$ tests of differences among means in performance tests between highest exposed quartile (TWA B-Pb $>2 \cdot 5 \mu \mathrm{mol} / \mathrm{l} ; n=13)$, moderately exposed $(T W A B-P b 1 \cdot 3$ to $2 \cdot 5 \mu \mathrm{mol} / l ; n=36)$ and referents $(B-P b<1.0$ umol/l)

\begin{tabular}{|c|c|c|c|c|c|c|c|c|c|c|}
\hline \multirow[t]{3}{*}{ Factor } & \multirow{2}{*}{\multicolumn{2}{|c|}{$\begin{array}{l}\text { Highest } \\
\text { exposed } \\
I\end{array}$}} & \multirow{2}{*}{\multicolumn{2}{|c|}{$\begin{array}{l}\text { Moderately } \\
\text { exposed } \\
\text { II }\end{array}$}} & \multicolumn{2}{|c|}{ Referents } & \multirow{3}{*}{$\begin{array}{l}p \\
I \\
I I\end{array}$} & \multirow{3}{*}{$\begin{array}{l}p \\
I I \\
\text { III }\end{array}$} & \multirow{3}{*}{$\begin{array}{l}p \\
I \\
I I I\end{array}$} & \multirow{3}{*}{$\begin{array}{l}p \\
I+I I \\
I I I\end{array}$} \\
\hline & & & & & \multicolumn{2}{|l|}{ III } & & & & \\
\hline & Mean & $S D$ & Mean & $S D$ & Mean & $S D$ & & & & \\
\hline $\begin{array}{l}\text { Logical } \\
\text { Perceptual speed } \\
\text { Psychomotor function } \\
\text { Memory } \\
\text { Learning } \\
\text { Reaction time }\end{array}$ & $\begin{array}{r}4 \cdot 6 \\
4 \cdot 4 \\
4 \cdot 1 \\
3 \cdot 2 \\
178 \\
423\end{array}$ & $\begin{array}{l}1 \cdot 7 \\
1 \cdot 5 \\
1 \cdot 3 \\
2 \cdot 5 \\
48 \\
57\end{array}$ & $\begin{array}{l}4 \cdot 6 \\
4 \cdot 5 \\
4 \cdot 2 \\
3 \cdot 5 \\
193 \\
410\end{array}$ & $\begin{array}{r}1.5 \\
1.6 \\
1.4 \\
1.9 \\
73 \\
104\end{array}$ & $\begin{array}{r}4 \cdot 7 \\
4 \cdot 9 \\
4 \cdot 4 \\
4 \cdot 6 \\
138 \\
376\end{array}$ & $\begin{array}{l}1 \cdot 7 \\
2 \cdot 1 \\
1 \cdot 3 \\
2 \cdot 0 \\
75 \\
60\end{array}$ & $\begin{array}{l}0.98 \\
0 \cdot 77 \\
0 \cdot 86 \\
0 \cdot 61 \\
0 \cdot 50 \\
0.57\end{array}$ & $\begin{array}{l}0 \cdot 76 \\
0 \cdot 37 \\
0 \cdot 54 \\
0 \cdot 03 \\
0 \cdot 01 \\
0 \cdot 11\end{array}$ & $\begin{array}{l}0.84 \\
0.38 \\
0.52 \\
0.05 \\
0.09 \\
0.02\end{array}$ & $\begin{array}{l}0.75 \\
0 \cdot 32 \\
0 \cdot 47 \\
0 \cdot 02 \\
0 \cdot 01 \\
0.04\end{array}$ \\
\hline
\end{tabular}

sample during the standardisation of the test battery was supposed to give a better description of the different intellectual functions covered by the battery than an analysis on the present sample would give. Factor scores were calculated for each subject as the unweighted mean of the age-adjusted stanine scores of the tests representing each factor-that is, vocabulary, logical function, perceptual speed, psychomotor function, and memory. The learning test and the reaction time test were handled as separate tests. The differences in factor scores were examined by successive $t$ tests.

The strength of possible dose-effect associations within the exposed group was analysed by product moment correlations between the different measures of exposure and the age-adjusted factor scores. Possible non-linear relations were explored by subgroupings of the exposed.

The differences in the proportion of positive answers between the exposed group and the referents in every single symptom question were examined by Chi-2-test with Yates's correction when the lowest expected number in each cell was greater than 4 . Otherwise Fisher's exact probability test was used. The differences in number of symptoms among the groups were analysed by analysis of variance. The differences and the correlations were regarded as statistically non-significant if the two-tailed $p$ value was $\geqslant 0 \cdot 05$.

\section{Results}

\section{COMPARISONS BETWEEN THE EXPOSED AND THE} UNEXPOSED GROUPS

The exposed group performed less well in 11 out of 14 non-verbal tests (table 1) compared with the referent group, and the overall difference between the groups was statistically significant when age-adjusted scores were used. The means and standard deviations of the factor scores, the learning test, and the reaction time test are presented in table 3 and are illustrated in the figure. The exposed group performed less well in all factors, but statistically significant differences were found only in the memory test, the learning test, and the reaction time test.

The exposed group reported significantly $(\mathrm{p}=$ $0.03)$ more symptoms than the referents $-4.7 v 2.9$. None in the referent group had more than six symptoms, which is the recommendation for further investigation when the questionnaire is used for screening in health check-up programmes, ${ }^{12}{ }^{15}$ while $13(27 \%)$ in the exposed group exceeded that value. The exposed group reported a higher proportion of symptoms to every question except on "problems with buttoning," which is included in the questionnaire as a check on response bias. ${ }^{12}{ }^{15}$ The greatest differences were shown in questions on irritability, reduced libido, depressiveness, and controlling (see table 4). An analysis of variance 
Table 4 Percentages and frequencies of reported symptoms in each question in questionnaire among exposed group $(n=49)$ and referents $(n=27)$. Differences are tested with Chi-square or Fisher's exact probability test



indicated that the number of symptoms was independent of age $(p=0 \cdot 56)$, which is in accordance with other studies using this questionnaire. ${ }^{12}$

\section{DOSE-EFFECT RELATIONS}

The dose-effect relations were studied by productmoment correlations. Neither the psychological factors nor the number of symptoms showed significant linear correlation with any of the exposure measures. Nevertheless, when the exposed group was

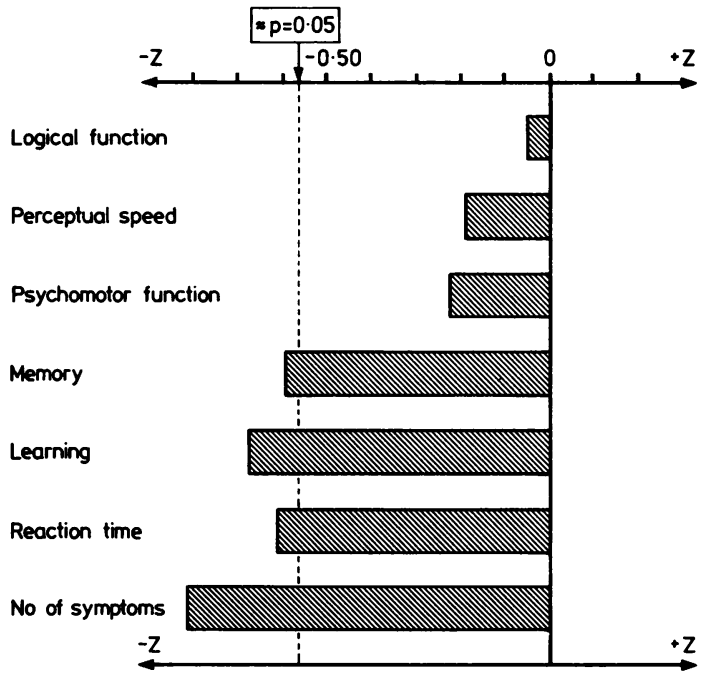

Performances of exposed group in relation to referent group. $Z$-score expresses difference among means in terms of standard deviation in referent group. A Z-score $<0$ means that average performance among exposed group is poorer than the average among referents. divided at the upper quartile of the time-weighted average of blood lead concentration (TWA B-Pb) a negative relation was shown in the test factors perceptual speed, psychomotor function, memory, and reaction time (table 3 ). In tests of memory and learning ability also the moderately exposed (TWA 1.3 to $2.5 \mu \mathrm{mol} / \mathrm{l}$ ) performed significantly less well than the referents.

The maximum value in $\mathrm{B}-\mathrm{Pb}$ as well as present $\mathrm{B}-\mathrm{Pb}$ concentration correlated with the TWA B-Pb ( $r=0.75$ and 0.33 respectively) but B-ZPP did not $(r=0 \cdot 15)$. Thus acute toxic effects cannot be separated from subchronic or chronic effects and the importance of single top exposures cannot be separated from the effects of long-time moderate exposure.

The subgroup that worked shift-time performed less well in every respect and reported more symptoms than the day-time workers. Since the number of shift workers was greater among the controls than among the exposed, the differences in performance might be underestimated. The proportion of shift workers in the highest exposed quartile, however, was equal to the proportion in the rest of the exposed and did not explain the demonstrated dose-effect relation.

\section{Discussion}

The exposed group performed worse than the control group, particularly in the tests of memory, learning, and visual reaction time, and reported more subjective symptoms. This test profile is coherent with other studies of lead-exposed workers. ${ }^{1-9}$

Within the exposed group the highest exposed quartile (TWA B-Pb $>2.5 \mu \mathrm{mol} / \mathrm{l}$ ) performed worst 
on tests of perceptual speed, psychomotor function, memory, and reaction time. The data do not support a linear relation between lead exposure and effects on the central nervous system, but rather a non-linear "terrace shaped" relation might be tentatively suggested and would be in line with some recent studies on animals. ${ }^{20-22}$ The possibility of partial reversibility of lead-induced impairment might further complicate the dose-effect relations.

It is of major importance for the interpretation of the results in this study that the exposed group and the referents were comparable in primary intellectual ability. A restriction regarding school education has been introduced, and an equally large ratio among the exposed and among the referents reported average school marks. The requirements of professional skill seemed equivalent in the two groups. Furthermore, the two groups performed comparably in verbal tests, clinically used as indicators of the primary ability. Army enrolment tests could be compared only for the younger subjects, but the exposed subgroup had results fairly comparable with the referents at the age of 19 . Thus it seems justified to regard the groups as intellectually comparable in their teens.

There were no indications of other neurotoxic influences in excess among the lead-exposed workers to confound the results. The employment times were longer among the exposed, and there were no reasons to believe that alcoholism would be overrepresented in this group.

The concentration of blood lead is not only affected by the air contamination but also by work practices and personal hygiene. If there was a relation between primary intelligence and personal hygiene then low performances might have caused high blood lead concentrations instead of the reverse interpretation. Nevertheless, there were no correlations between test-scores at the age of 19 and the highest value in blood lead during the control period among the 18 exposed subjects tested at army enrolment.

Cross-sectional studies might underestimate adverse health effects since people with greater impairments and serious symptoms do not remain in the working population. A lower motivation among the referents than among the exposed is also common in these types of studies, but in this study the same introduction and information about the purpose of the study were given to both groups. A larger number of shift workers among the referents might also have diminished the performance differences between the groups.

These results support other studies of lead-exposed workers and indicate central nervous impairment from blood lead concentrations of $2 \cdot 3$ to $2 \cdot 5 \mu \mathrm{mol} / \mathrm{l}$.
Irrespective of whether the impaired performances on psychological tests and the neuropsychiatric symptoms shown in this study are permanent or reversible, the average blood lead concentration should be below $2.5 \mu \mathrm{mol} / \mathrm{l}$ to avoid these adverse effects.

We are most grateful to Mrs Inger Fagerlund and Kjell Lindkvist for technical help. The project was partly financed by the Swedish Work Environment Fund, contract number 78/299.

\section{References}

' Repko JD, Morgan BB, Nicholson JA. Final report on the behavioural effects of occupational exposure to lead. Louisville: Performance Research Laboratory, Graduate School, University of Louisville, 1974. (Interim technical report No ITR 74-27.)

${ }^{2}$ Repko JD, Corum CR, Jones PD, Garcia LS. The effects of inorganic lead on behavioural and neurologic function. Ohio: US DHEW, 1978. (NIOSH publ No 78-128.)

${ }^{3}$ Lilis R, Fischbein A, Eisinger J, et al. Prevalence of lead disease among secondary lead smelter workers and biological indicators of lead exposures. Environ Research 1977;14:255-85.

${ }^{4}$ Hänninen H, Hernberg S, Mantere P, Vesanto R, Jalkanen M. Psychological performance of subjects with low exposure to lead. JOM 1978;20:638-9.

5 Valciukas JA, Lilis R, Eisinger J, Blumberg WE, Fischbein A, Selikoff IJ. Behavioural indicators of lead neurotoxicity: results of a clinical field survey. Int Arch Occup Environ Health 1978;41:217-36.

- Grandjean P, Arnveig E, Beckmann J. Psychological dysfunctions in lead exposed workers. Scand J Work Environ Health 1978;4:295-303.

${ }^{7}$ Mantere P, Hänninen H, Hernberg S, Martelin T. Exposureresponse relationship for neurotoxic lead effects: psychological performance in a one year follow-up study. Activ Nerv Super (Praha) 1979;21:292-3.

${ }^{8}$ Lilis R, Fischbein A, Diamond S. Lead effects among secondary lead smelter workers with blood lead levels below $80 \mu \mathrm{g} / 100 \mathrm{ml}$. Arch Environ Health 1977;32:256-66.

๑ Hänninen H, Mantere P, Hernberg S, Seppäläinen AM, Kock B. Subjective symptoms in low-level exposure to lead. Neurotoxicology 1979;1:333-47.

${ }^{10}$ Blumburg WE, Wisinger J, Lamola AA, Zuckerman DM. Zinc protoporphyrin level in blood determined by a portable hematofluorometer: a screening device for lead poisoning. $J$ Lab Clin Med 1977;89:712-23.

1 Sjöborg A. Frömark A. Standardisering av ett psykologiskt testbatteri för beteendetoxikologiska undersökningar (Standardisation of a battery of psychological tests for researches in behavioural toxicology). Stockholm: Psykotekniska Institutet, 1977. (Information frân PTI nr 93 1977.)

${ }^{12}$ Hogstedt C, Hane M, Axelson O. Diagnostic and health care aspects of workers exposed to solvents. In: Zenz $C$, ed. Developments in occupational medicine. Chicago: Year Book Medical Publishers, Inc, 1980.

${ }^{13}$ Claeson L, Esbjörnsson E, Carlé B, Wahlbin M. Claeson-Dahls inlärningstest för kliniskt bruk (Claeson-Dahl's learning test for clinical use). Stockholm: Skandinaviska Testförlaget, 1971.

14 Valciukas JA, Lilis R. Psychometric techniques in environmental research. Environ Research 1980;21:275-97.

${ }^{15}$ Hogstedt C, Andersson K, Hane M. A questionnaire approach to the monitoring of early disturbances in central nervous 
functions. In: Aitio A, Rihimäki $\mathrm{V}$, Vainio $\mathrm{H}$, eds. The biological monitoring of exposure to industrial chemicals. Washington: Hemisphere Publishing Corporation (in press).

${ }^{16}$ Agrell A, Hane M, Hogstedt C. Symptoms among house painters-a five-year follow up study. Läkartidningen 1980;77:440-2. (English abstract.)

17 Morrison DF. Multivariate statistical methods. New York: McGraw-Hill Book Company, 1967.

${ }^{18}$ Elofsson S-A, Gamberale F, Hindmarsh T, et al. Exposure to organic solvents. A cross-sectional epidemiologic investigation on occupationally exposed car and industry spray painters with special reference to the nervous system. Scand J Work Environ Health 1980;6:239-73.
${ }^{19}$ Frömark A, Gamberale F, Sjöborg A. A battery of psychological tests for researches in behavioural toxicology. Stockholm: Psykotekniska Institutet, 1979. (Rapport 104.)

${ }^{20}$ Savolainen H, Kilpiö J. Brain and blood lead in acute intoxication. Scand J Work Environ Health 1977;3:104-7.

${ }^{21}$ Hietanen E, Kilpiö J, Koivusaari U, et al. Neurotoxicity of lead in rabbits. In: Holmstedt B, Lauwerys R, Mercier M, Roberfroid $\mathrm{M}$, eds. Mechanisms of toxicity and hazard evaluation. Amsterdam: Elsevier North-Holland Biomedical Press, 1980.

${ }^{22}$ Hrdina P, Hanin I, Dubas T. Neurochemical correlates of lead toxicity. In: Singhal R, Thomas J, eds. Lead toxicity. Baltimore: Urban \& Schwarzenberg, 1980. 